Article

\title{
Differential Activation of Glioprotective Intracellular Signaling Pathways in Primary Optic Nerve Head Astrocytes after Treatment with Different Classes of Antioxidants
}

\author{
Anita K. Ghosh ${ }^{1,2}$, Vidhya R. Rao ${ }^{2,3}$, Victoria J. Wisniewski ${ }^{4}$, Alexandra D. Zigrossi ${ }^{3}$, \\ Jamie Floss ${ }^{4}$, Peter Koulen ${ }^{5}$, Evan B Stubbs Jr. ${ }^{2,3}$ and Simon Kaja ${ }^{2,3,4, *(D)}$ \\ 1 Graduate Program in Biochemistry and Molecular Biology, Loyola University Chicago, Health Sciences \\ Campus, Maywood, IL 60153, USA; aghosh3@luc.edu \\ 2 Research Service, Edward Hines Jr. Veterans Administration Hospital, Hines, IL 60141, USA; \\ vrao2@luc.edu (V.R.R.); evan.stubbs@va.gov (E.B.S.J.) \\ 3 Department of Ophthalmology, Loyola University Chicago, Stritch School of Medicine, Maywood, IL 60153, \\ USA; ahegel@luc.edu \\ 4 Department of Molecular Pharmacology and Neuroscience, Loyola University Chicago, Stritch School of \\ Medicine, Maywood, IL 60153, USA; vicki1102127@gmail.com (V.J.W.); jfloss61@gmail.com (J.F.) \\ 5 Department of Ophthalmology and Biomedical Sciences, Vision Research Center, University of \\ Missouri-Kansas City, School of Medicine, Vision Research Center, Kansas City, MO 64108, USA; \\ koulenp@umkc.edu \\ * Correspondence: skaja@luc.edu; Tel.: +1-708-216-9223
}

Received: 22 March 2020; Accepted: 14 April 2020; Published: 16 April 2020

\begin{abstract}
Optic nerve head astrocytes are the specialized glia cells that provide structural and trophic support to the optic nerve head. In response to cellular injury, optic nerve head astrocytes undergo reactive astrocytosis, the process of cellular activation associated with cytoskeletal remodeling, increases in the rate of proliferation and motility, and the generation of Reactive Oxygen Species. Antioxidant intervention has previously been proposed as a therapeutic approach for glaucomatous optic neuropathy, however, little is known regarding the response of optic nerve head astrocytes to antioxidants under physiological versus pathological conditions. The goal of this study was to determine the effects of three different antioxidants, manganese (III) tetrakis (1-methyl-4-pyridyl) porphyrin (Mn-TM-2-PyP), resveratrol and xanthohumol in primary optic nerve head astrocytes. Effects on the expression of the master regulator nuclear factor erythroid 2-related factor 2 (Nrf2), the antioxidant enzyme, manganese-dependent superoxide dismutase 2 (SOD2), and the pro-oxidant enzyme, nicotinamide adenine dinucleotide phosphate oxidase 4 (NOX4), were determined by quantitative immunoblotting. Furthermore, efficacy in preventing chemically and reactive astrocytosis-induced increases in cellular oxidative stress was quantified using cell viability assays. The results were compared to the effects of the prototypic antioxidant, Trolox. Antioxidants elicited highly differential changes in the expression levels of Nrf2, SOD2, and NOX4. Notably, Mn-TM-2-PyP increased SOD2 expression eight-fold, while resveratrol increased Nrf2 expression three-fold. In contrast, xanthohumol exerted no statistically significant changes in expression levels. 3-(4,5-dimethylthiazol-2-yl)-2,5-diphenyltetrazolium bromide (MTT) uptake and lactate dehydrogenase $(\mathrm{LDH})$ release assays were performed to assess cell viability after chemically and reactive astrocytosis-induced oxidative stress. Mn-TM-2-PyP exerted the most potent glioprotection by fully preventing the loss of cell viability, whereas resveratrol and xanthohumol partially restored cell viability. Our data provide the first evidence for a well-developed antioxidant defense system in optic nerve head astrocytes, which can be pharmacologically targeted by different classes of antioxidants.
\end{abstract}


Keywords: glioprotection; xanthohumol; resveratrol; manganese porphyrin; optic nerve head astrocytes; phase II antioxidant enzymes; cell viability

\section{Introduction}

Optic nerve head astrocytes are the specialized glia cells that provide structural and trophic support to the unmyelinated optic nerve head. The optic nerve head is the point of exit where axons of retinal ganglion cells leave the eye to form the axons of the optic nerve. Over the past few decades, complex signaling pathways have been identified in astrocytes that were previously thought to be restricted to neurons, including complex calcium signaling pathways [1]. Knowledge of the specific intracellular signaling pathways in optic nerve head astrocytes, however, remains limited and, due to the unique biomechanical environment of the optic nerve head, the translatability of findings from other types of astrocytes is limited.

In response to cellular triggers that can include biomechanical, bioenergetic and biochemical changes, optic nerve head astrocytes undergo reactive astrocytosis (also commonly referred to as astrogliosis) [2-4]. This cellular activation is associated with cytoskeletal remodeling, increases in the rate of proliferation and motility, and generation of Reactive Oxygen Species.

Previous studies by us and others have shown that primary optic nerve head astrocytes are vulnerable to the deleterious effects of oxidative stress and that antioxidants can protect against chemically induced oxidative stress [5-8]. Investigations into the underlying mechanisms, however, have primarily focused on the expression of apoptosis-related genes and proteins, such as caspases, Bcl-2, Bcl-2-associated protein and related signaling pathways [9,10].

The Kelch-like ECH-associated protein 1/nuclear factor erythroid 2 related factor 2/antioxidant response element (Keap1/Nrf2/ARE) pathway is the master regulator of phase II antioxidant enzymes, a group of enzymes critical for the endogenous antioxidant response (for review, see [11]). Pharmaceutical modulation of this pathway is of significant interest for the treatment of neurological, neurodegenerative and neuroimmunological disorders.

Therefore, the goal of the present study was to determine whether different classes of antioxidants can elicit selective responses in the endogenous antioxidant system and whether they exert glioprotective effects in optic nerve head astrocytes against both chemically induced and reactive astrocytosis-associated increases in oxidative stress.

For this study, three different antioxidants were evaluated: manganese (III) tetrakis (1-methyl-4-pyridyl) porphyrin (Mn-TM-2-PyP), resveratrol, and xanthohumol. The effects of these antioxidants were compared to the prototypic antioxidant, 6-hydroxy-2,5,7,8-tetramethylchroman-2-carboxylic acid (Trolox).

Mn-TM-2-PyP is a superoxide dismutase (SOD) mimetic that belongs to the metalloporphyrin group and possesses broad antioxidant specificity, which includes scavenging $\mathrm{O}_{2}{ }^{-}{ }^{-}, \mathrm{H}_{2} \mathrm{O}_{2}, \mathrm{ONOO}^{-}$, $\mathrm{NO}$, and lipid peroxyl radicals [12]. Manganese porphyrins are well characterized and offer protection in a variety of oxidative stress injuries such as stroke, diabetes, radiation injury, dry eye disease and ischemia [13-19].

Resveratrol is a stilbenoid polyphenol, well-known for its abundance in grape skin, where it is produced under injurious conditions [20]. There is controversy over the specific molecular mechanism of action of resveratrol. Data suggest several distinct pathways contributing to the tissue-specific effects of resveratrol, including its direct Reactive Oxygen Species (ROS) scavenging activity, the modulation of the endogenous antioxidant system through Nrf2 upregulation [21,22], and control over apoptosis-related genes.

Xanthohumol is a naturally occurring prenylated chalconoid abundantly present in Humulus lupulus, the hops plant. Xanthohumol exerts its antioxidant effects by stimulating the 
dissociation of Keap1 from Nrf2, allowing Nrf2 to translocate into the nucleus and bind the ARE, ultimately promoting the transcription of phase II antioxidant enzymes [23].

Lastly, Trolox is a water-soluble analog of vitamin E and ROS scavenger. Trolox is the most commonly used reference standard for the antioxidant capacity of compounds [24], partly due to its lack of modulation of intracellular antioxidant enzymes [25].

\section{Materials and Methods}

\subsection{Antioxidants and Antibodies}

Resveratrol and xanthohumol were purchased from Cayman Chemicals (Ann Arbor, MI, USA). Trolox and Mn-TM-2-PyP were obtained from Millipore Sigma (St. Louis, MO, USA). For experiments, resveratrol and xanthohumol were dissolved in dimethyl sulfoxide (Millipore Sigma, St. Louis, MO, USA), Mn-TM-2-PyP was dissolved in 0.1 M phosphate-buffered saline $\mathrm{pH} 7.4$ (PBS) and Trolox was dissolved in ethanol.

The following antibodies were used for immunoblotting experiments: chicken anti-glial fibrillary acid protein (GFAP; ab4674; AbCam, Cambridge, MA, USA; 1:5000 dilution); rabbit anti-Nox4 (ab133303; AbCam; 1:5000 dilution); mouse anti-Nrf2 (VMA00224; Biorad Laboratories, Hercules, CA; 1:1000 dilution); rabbit anti-Sod2 (A1340; ABclonal, Woburn, MA; 1:2000 dilution). Glyceraldehyde-3-phosphate dehydrogenase (GAPDH) was used as endogenous control (rabbit anti-GAPDH; sc-25778; Santa Cruz Biotechnology, Dallas, TX; 1:2000 dilution). Secondary antibodies were horseradish peroxidase-conjugated and obtained from GE Healthcare (Chicago, IL, USA).

Immunocytochemistry was performed using chicken anti-glial fibrillary acid protein (GFAP; ab4674; AbCam; 1:1000 dilution) and Alexa Fluor ${ }^{\circledR}$ 594-labeled goat anti-chicken secondary antibody (Thermo Fisher Scientific, Waltham, MA, USA).

\subsection{Primary Culture of Optic Nerve Head Astrocytes}

Primary cultures of adult rat optic nerve head astrocytes were maintained and validated as we have previously described in detail $[5,6,26]$. Cultures of passages 10 to 20 were used for experiments.

\subsection{Induction of Reactive Astrocytosis}

Optic nerve head astrocyte cultures were seeded at a density of 25,000 cells $/ \mathrm{cm}^{2}$ in 6-well plates (TPP; Midwest Scientific, Valley Park, MO, USA). Cultures were exposed to 25-35 mm Hg pressure above ambient pressure for $16 \mathrm{~h}$ in a custom-built, vacuum-sealed hyperbaric pressure chamber placed inside of a $37^{\circ} \mathrm{C}$ tissue culture incubator. Pressure was monitored through a liquid-immersed pressure sensor (Harvard Apparatus, Holliston, MA, USA), connected to a laptop computer running PowerLab $8 / 35$ high-performance data acquisition system supplied with LabChart Pro software and modules (ADInstruments, Colorado Springs, CO, USA). Cultures were returned to ambient pressure for $1 \mathrm{~h}$ prior to experiments.

\subsection{Protein Extraction and Immunoblotting}

Media was aspirated and cells were washed and scraped in ice-cold PBS. Samples were centrifuged at $800 \times \mathrm{g}$ for $5 \mathrm{~min}$; supernatant was aspirated, and pellets were lysed in five volumes of Cytobuster lysis reagent (Millipore Sigma St. Louis, MO, USA) supplemented with a protease inhibitor cocktail (Thermo Fisher Scientific, Waltham, MA, USA). Lysates were triturated with a 31-gauge insulin syringe and subsequently centrifuged at $16,000 \times g$ for $10 \mathrm{~min}$ to remove cell debris. The protein concentrations of lysates were determined using the method of Lowry [27].

For immunoblotting, protein samples with loading buffer were denatured at $85{ }^{\circ} \mathrm{C}$ for $5 \mathrm{~min}$. A total of $5-10 \mu \mathrm{g}$ of each protein sample was loaded on pre-cast $4-12 \%$ NuPage ${ }^{\circledR}$ Bis/Tris gels (Thermo Fisher Scientific, Waltham, MA, USA) and electrophoresed at $150 \mathrm{~V}$ for $75 \mathrm{~min}$. Proteins were transferred from gels to nitrocellulose membrane with $0.2 \mu \mathrm{M}$ pore size (Amersham Protran, 
GE Healthcare, Chicago, IL, USA) by wet-transfer using Pierce ${ }^{\mathrm{TM}}$ Methanol-free Western Blot Transfer Buffer (Thermo Fisher Scientific, Waltham, MA, USA) at $100 \mathrm{~V}$ for $90 \mathrm{~min}$. Membranes were blocked in 5\% non-fat milk in PBS supplemented with 0.2\% Tween-20 (PBS-T; Millipore Sigma, St. Louis, MO, USA), then incubated with primary antibody in $2.5 \%$ milk in PBS-T at $4{ }^{\circ} \mathrm{C}$ overnight while gently shaking. All primary antibodies used are listed in Section 2.1 with catalog numbers and dilutions; GAPDH was used as an endogenous control for all experiments. Membranes were washed three times in PBS-T then subsequently incubated with horseradish peroxidase-linked secondary antibody in 2.5\% milk in PBS-T at room temperature for $1 \mathrm{~h}$. Immunoblot detection was performed by chemiluminescence using the Luminata Forte ${ }^{\circledR}$ reagent (Millipore Sigma, St. Louis, MO, USA). Images were acquired using a ChemiDoc ${ }^{\mathrm{TM}}$ XRS+ System (Bio-Rad Laboratories, Hercules, CA, USA). Protein bands were analyzed by densitometry using either Image Lab software (Bio-Rad Laboratories, Hercules, CA, USA) or Fiji software (ImageJ, NIH, Bethesda, MD, USA), and normalized to GAPDH and the control condition.

\subsection{Immunocytochemistry}

Optic nerve head astrocytes were seeded on either black/clear bottom 96-well plates or 8-well chamber slides at a density of 25,000 cells $/ \mathrm{cm}^{2}$. After two days, cells were rinsed in $100 \mu \mathrm{L}$ PBS and subsequently fixed in 4\% paraformaldehyde (PFA) in PBS for 15 min. Cultures were immunostained as described by us previously [26]. Cells were co-labeled with DAPI (NucBlue ${ }^{\mathrm{TM}}$ Fixed Cell ReadyProbes ${ }^{\mathrm{TM}}$ Reagent, Thermo Fisher Scientific, Waltham, MA, USA) to label cell nuclei. Images were acquired using a plate reader (Cytation5, Biotek, Winooski, VT, USA) or Leica SP5 confocal microscope (Leica Microsystems Inc., Buffalo Grove, IL, USA). Immunocytochemistry was analyzed by microfluorimetry using Fiji software, as described by our laboratory previously [28].

\subsection{Filamentous and Globular Actin Staining}

To label astrocyte cultures for filamentous (F-) and globular (G-) actin, cells were seeded on black/clear bottom 96-well plates or 8-well chamber slides at a density of $25,000 \mathrm{cells} / \mathrm{cm}^{2}$. After treatments, cells were rinsed in PBS then fixed in 4\% PFA for $15 \mathrm{~min}$. Cells were subsequently washed $3 \times$ in PBS for 5 min each, then permeabilized in $0.1 \%$ Triton-X 100 for $5 \mathrm{~min}$. Stain solution was prepared by adding two drops of ActinGreen ${ }^{\mathrm{TM}}$ ReadyProbes ${ }^{\mathrm{TM}}$ Reagent (Thermo Fisher Scientific, Waltham, MA, USA) for filamentous (F-) actin and two drops of NucBlue ${ }^{\mathrm{TM}}$ Fixed Cell ReadyProbes ${ }^{\mathrm{TM}}$ Reagent (Thermo Fisher Scientific, Waltham, MA, USA) to stain nuclei, per $1 \mathrm{~mL}$ of PBS. Alexa Fluor ${ }^{\mathrm{TM}}$ 594 conjugated DNAseI (Thermo Fisher Scientific, Waltham, MA, USA) to stain globular (G-) actin was added to the stain solution for a final concentration of $0.3 \mu \mathrm{M}$, per the manufacturer's instructions. A total of $100 \mu \mathrm{l}$ stain solution was added to each well and incubated for $30 \mathrm{~min}$ at room temperature in the dark. Cells were again washed $3 \times$ in PBS. Images were acquired using a plate reader (Cytation5, Biotek, Winooski, VT, USA).

F-actin fiber length was quantified using Matlab (Mathworks, Natick, MA, USA), with exclusion criteria set to fibers of $<15 \mu \mathrm{m}$ and $>250 \mu \mathrm{m}$ length, based on mathematical outlier considerations. The average fiber length for each condition was determined by averaging data from 10 images per well and 8 - 16 wells per treatment condition. The intensity of G-actin immunolabel was quantified in Matlab (Mathworks) by thresholding the image and determining mean intensity per area. The average G-actin expression for each condition was determined by averaging intensity data from 10 images per well and 8-16 wells per treatment condition.

\subsection{Quantification of Oxidative Stress Using CellROX ${ }^{\circledR}$ Green}

Optic nerve head astrocytes were seeded in 8-well chamber slides at a density of $25,000 \mathrm{cells} / \mathrm{cm}^{2}$. After the desired treatment, CellROX ${ }^{\circledR}$ Green was added to the wells at a final concentration of $5 \mu \mathrm{M}$ in complete medium and incubated with the cells for $30 \mathrm{~min}$ at $37^{\circ} \mathrm{C}$. Media with CellROX ${ }^{\circledR}$ reagent was removed from the wells by aspiration and cells were rinsed $3 \times$ in PBS. Cells were fixed in $4 \%$ 
PFA for $15 \mathrm{~min}$, then rinsed again $3 \times$ in PBS. Cells were subsequently permeabilized in $0.1 \%$ Triton X-100 for 5 min. Nuclei were stained with NucBlue ${ }^{\mathrm{TM}}$ Fixed Cell ReadyProbes ${ }^{\mathrm{TM}}$ Reagent (Thermo Fisher Scientific, Waltham, MA, USA) at 2 drops per $\mathrm{ml}$ of PBS. Cells were rinsed $3 \times$ in PBS. Chamber slides were mounted by placing a coverslip onto the slide using Aqua-Poly/Mount (Polysciences Inc., Warrington, PA, USA). Images were acquired using a Leica SPE confocal microscope (Leica Microsystems Inc., Buffalo Grove, IL, USA).

CellROX $^{\circledR}$ Green fluorescent area was quantified using Fiji software. Briefly, images were converted to 8-bit grayscale and thresholded. The thresholded image was converted into a binary image and an image mask outlining the nuclei created. Analogously, the channel with CellROX ${ }^{\circledR}$ fluorescence was thresholded and the nuclei mask was overlaid. The percent area of nuclear fluorescence was quantified by dividing the area of fluorescence by the total nuclear area. Data are from 10 images per well, and 3-4 separate wells were analyzed per experiment.

\subsection{Quantification of Oxidative Stress Using Dichlorofluorescein}

For quantification of ROS using the dichlorofluorescein method, optic nerve head astrocytes were seeded in 96-well plates at a density of $25,000 \mathrm{cells} / \mathrm{cm}^{2}$ and incubated overnight. Media was removed and cells were incubated with $5 \mu \mathrm{M}$ 6-carboxy-2', $7^{\prime}$-dichlorodihydrofluorescein diacetate (Carboxy- $\mathrm{H}_{2}$ DCFDA, Thermo Fisher Scientific, Waltham, MA, USA) in HBSS supplemented with $10 \mathrm{mM}$ HEPES at $37^{\circ} \mathrm{C}$ for $30 \mathrm{~min}$. Subsequently, cell supernatant was removed and replaced by complete medium. Following a 30-min incubation, cells were exposed to the desired treatments. After treatments, dichlorofluorescein fluorescence, the product of cleavage of Carboxy- $\mathrm{H}_{2} \mathrm{DCFDA}$ by ROS, was measured at $488 \mathrm{~nm}$ excitation/ $520 \mathrm{~nm}$ emission using a plate reader (Cytation5, Biotek, Winooski, VT, USA).

\subsection{Cell Viability Assays}

To determine the glioprotective effects of antioxidants on reactive astrocytosis, we conducted 3-(4,5-dimethylthiazol-2-yl)-2,5-diphenyltetrazolium bromide (MTT) uptake and lactate de-hydrogenase (LDH) release assays were performed, as previously described by us in detail $[5,6]$. In brief, supernatants $(50 \mu \mathrm{L})$ were collected and LDH assays performed. Cells were incubated with MTT dye for $1.5 \mathrm{~h}$ and subsequently lysed in dimethylsulfoxide (DMSO). Data were normalized to the baseline control condition and expressed as fold-change.

\subsection{Data Analysis and Statistics}

All data were analyzed, with the investigator blinded to treatment group. For immunoblotting, all samples were assigned a random number and samples were loaded in random order on acrylamide gels to minimize technical and investigator bias. Data are presented as mean \pm standard error of mean (SEM). Open and filled circles represent individual data points. Data were analyzed using paired or unpaired Student's $t$-test, one-way analysis of variance (ANOVA) or Kruskal-Wallis ANOVA, or Two-Way ANOVA. Differences between groups were subsequently determined using either Tukey's, Dunn's, or Sidak's multiple comparison test, as appropriate. Differences were considered statistically significant at the $p<0.05$ level.

\section{Results}

\subsection{Reactive Astrocytosis Causes Cytoskeletal Remodeling and Generation of Increased Cellular Levels of Oxidative Stress}

Astrocytes undergoing reactive astrocytosis display a myriad of distinct biochemical and functional phenotypes, including cytoskeletal remodeling and excess generation of cellular oxidative stress. In order to induce a cellular phenotype of reactive astrocytosis, optic nerve head astrocytes were exposed to hyperbaric pressure at $35 \mathrm{~mm} \mathrm{Hg}$ above ambient pressure for a period of $16 \mathrm{~h}$ in 
a hyperbaric pressure chamber at $37^{\circ} \mathrm{C}$ and $5 \% \mathrm{CO}_{2} / 95 \%$ humidity. Control cultures were maintained at ambient pressure.

Induction of reactive astrocytosis resulted in significantly elevated GFAP levels (Figure 1A-B,F). Intensity of GFAP immunoreactivity increased 4.52-fold in reactive astrocytosis compared with control optic nerve head astrocytes $(n=21-22, p<0.01$, Figure 1A). These results were confirmed by quantitative immunoblot for GFAP, which revealed a 1.63-fold increase in expression of $\operatorname{GFAP}(n=3, p<0.05$, Figure 1B).
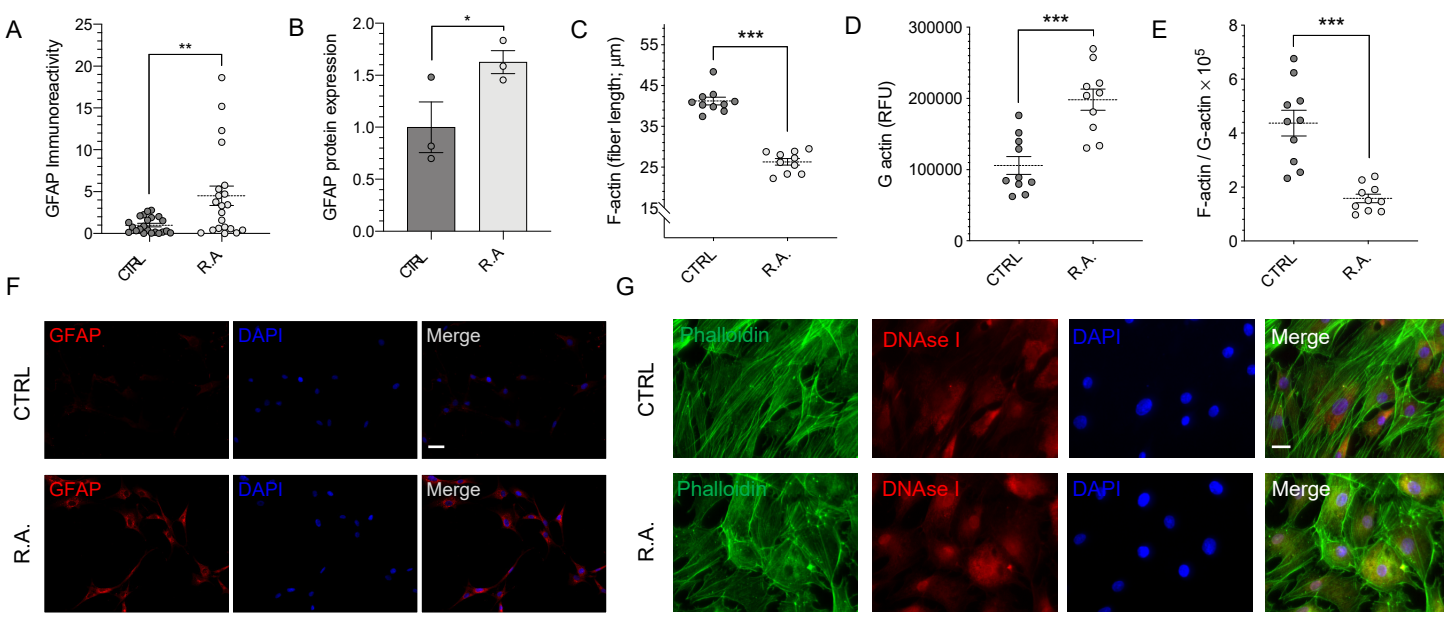

Figure 1. Reactive astrocytosis results in cytoskeletal remodeling. (A) anti-glial fibrillary acid protein (GFAP) immunoreactivity was quantified by fluorimetry. A statistically significant increase in GFAP immunoreactivity was observed in activated astrocytes compared to control $(n=20-21 ; p<0.01)$. (B) Quantitative immunoblot analysis revealed a statistically significant increase in GFAP protein expression in activated astrocytes $(n=3 ; p<0.05)$. (C) Quantification of individual F-actin fiber lengths revealed a statistically significant $36 \% \pm 2 \%$ decrease in activated optic nerve head astrocytes $(n=10 ; p<0.001)$. (D) A statistically significant $87 \% \pm 12 \%$ increase in G-actin immunofluorescence was observed in activated astrocytes $(n=10 ; p<0.001)$. (E) The F-actin to G-actin ratio showed a statistically significant decrease in activated astrocytes $(n=10, p<0.001)$. (F) Representative images of GFAP immunocytochemistry. (G) Representative images of actin staining. Oligomeric F-actin and monomeric G-actin were visualized using ActinGreen ${ }^{\mathrm{TM}}$ ReadyProbes ${ }^{\mathrm{TM}}$ Reagent and Alexa Fluor $^{\mathrm{TM}}$ 594 conjugated DNAseI, respectively. Data were analyzed by Student's $t$-test; ${ }^{*} p<0.05,{ }^{* *} p<0.01$, *** $p<0.001$. Scale bar: (F) $25 \mu \mathrm{m},(\mathbf{G}) 10 \mu \mathrm{m}$. CTRL = control; R.A. = reactive astrocytosis.

To determine the effect of reactive astrocytosis on the actin cytoskeleton, optic nerve head astrocytes were labeled with fluorescently-conjugated phalloidin to detect F-actin and DNAse I to detect G-actin. Control astrocytes exhibited long, parallel bundles of actin filaments with modest G-actin expression; activated optic nerve head astrocytes, in contrast, showed significant disorganization of F-actin filaments (Figure 1G). The quantification of F-actin individual fiber length revealed a $36 \% \pm 2 \%$ shortening of actin fibers in activated optic nerve head astrocytes $(41.2 \pm 0.9 \mu \mathrm{m} ; n=10)$ compared with control $(26.3 \pm 0.8 \mu \mathrm{m}, n=10 ; p<0.001$; Figure 1C). This actin fiber shortening was associated with a concomitant $87 \% \pm 12 \%$ increase in the expression levels of monomeric G-actin, as determined by fluorimetry $(n=10, p<0.001$; Figure $1 \mathrm{D}, \mathrm{G})$. In order to test the dependence of the two parameters, the ratio of F-actin fiber length to G-actin expression was calculated, revealing a $68.2 \% \pm 3.6 \%$ reduction associated with reactive astrocytosis $(n=10, p<0.001$; Figure $1 \mathrm{E})$.

Cellular levels of oxidative stress were detected using CellROX ${ }^{\circledR}$ Green. Reactive astrocytosis resulted in significant nuclear and cytosolic fluorescence, indicative of elevated cellular levels of oxidative stress that could be prevented by pre-treatment with the prototypic antioxidant, Trolox (Figure 2A). CellROX ${ }^{\circledR}$ Green staining was quantified by estimating the percentage of the total nuclear area covered by fluorescent CellROX ${ }^{\circledR}$ signal (Figure 2B). Reactive astrocytosis increased nuclear fluorescence $4.6 \pm 0.6$-fold (from $10.4 \%$ in control to $47.9 \%$ in activated astrocytes; $n=7$; 
ANOVA $p<0.001$; Tukey's multiple comparisons test, $p<0.001)$, while pre-treatment with Trolox reduced the area of nuclear fluorescence to $28.6 \pm 0.1 \%$ of baseline $(n=7, p<0.001$; Figure 2B).

A

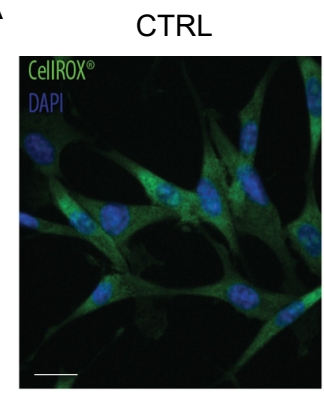

C

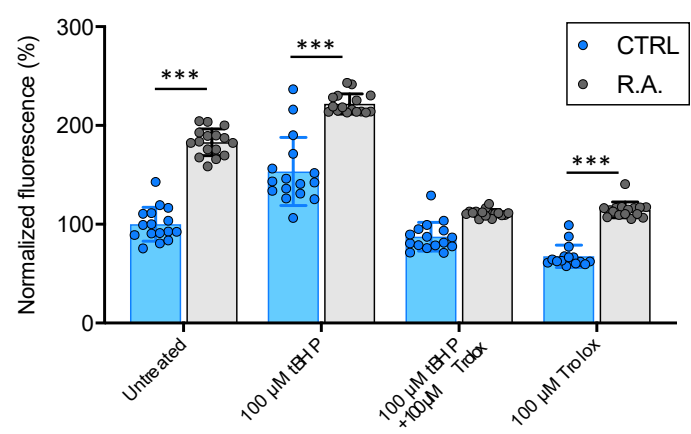

R.A.

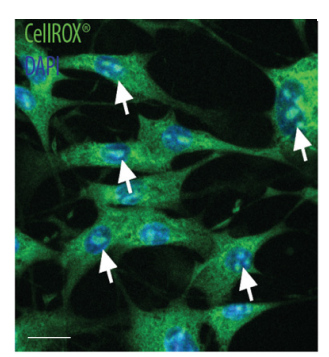

R.A. + $100 \mu \mathrm{M}$ Trolox

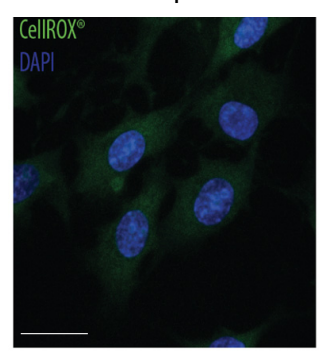

$\mathrm{D}$

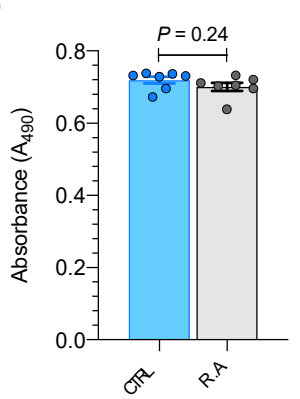

B

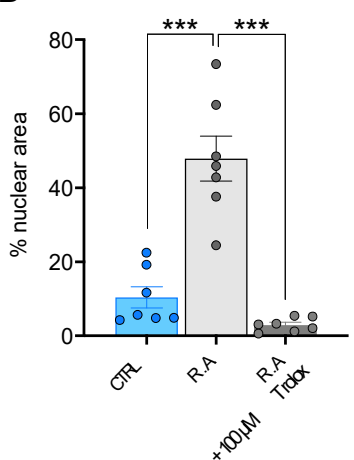

E

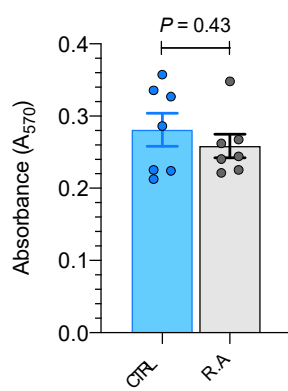

Figure 2. Reactive astrocytosis results in elevated cellular levels of oxidative stress. (A) Representative images of CellROX ${ }^{\circledR}$ Green staining for ROS generation. Increased nuclear and cytosolic fluorescence were observed in activated optic nerve head astrocytes compared to control. Pretreatment with $100 \mu \mathrm{M}$ Trolox for $1 \mathrm{~h}$ prior to the induction of reactive astrocytosis prevented this increase in oxidative stress. White arrows point to nuclear fluorescence indicative of ROS generation. (B) ROS generation was quantified as percentage of nuclear area covered by CellROX ${ }^{\circledR}$ Green fluorescence $(n=7$; One-Way ANOVA with Tukey's multiple comparisons test, $p<0.001)$. Trolox prevented this increase $(n=7 ; P<0.001)$. (C) Dichlorofluorescein fluorescence increased significantly during reactive astrocytosis $(n=16, p<0.001)$. Pretreatment with a sublethal $(100 \mu \mathrm{M})$ dose of $t \mathrm{BHP}$ for $1 \mathrm{~h}$ prior to and during induction of reactive astrocytosis further increased cellular levels of oxidative stress $(n=16, p<0.001)$. Trolox prevented both the tBHP- and reactive-astrocytosis-induced upregulation of oxidative stress $(p>0.05)$. Sixteen individual replicate datapoints are shown, representative of three separate experiments. Data were analyzed by Two-Way ANOVA $(p<0.001)$ with results from Sidak's multiple comparisons test indicated by asterisks. (D) Induction of reactive astrocytosis did not result in a loss of cell viability, as determined by comparing absolute $\mathrm{LDH}$ release by measuring $\mathrm{A}_{490}$ in control and activated optic nerve head astrocytes $(n=7, p=0.24)$. (E) Similarly, there was no statistically significant difference in MTT absorbance $\left(\mathrm{A}_{570}\right)$ between control and activated optic nerve head astrocytes $(n=7, p=0.43)$. Data are shown as mean \pm s.e.m. ${ }^{* * *} p<0.001$. CTRL $=$ control; R.A. $=$ reactive astrocytosis. Scale bar $=10 \mu \mathrm{m}$.

Results from the semi-quantitative CellROX ${ }^{\circledR}$ assay were confirmed by the plate reader-based quantification of dichlorofluorescein labeling. Reactive astrocytosis increased dichlorofluorescein fluorescence intensity by $83 \% \pm 14 \%(n=16, p<0.001$; Figure 2C) compared to control. The exposure of cultures to a sublethal $(100 \mu \mathrm{M})$ concentration of $t \mathrm{BHP}$ resulted in a $53 \% \pm 35 \%$ increase in fluorescence compared with control untreated optic nerve head astrocytes ( $n=16, p<0.001$; Figure 2C). Reactive astrocytosis further increased fluorescence to $122 \% \pm 10 \%$ of control untreated cells $(n=3$, $p<0.001$; Figure 2C). Trolox prevented both $t \mathrm{BHP}$ - and reactive-astrocytosis-induced increases in dichlorofluorescein fluorescence ( $p>0.05$; Figure 2C).

In order to determine whether reactive astrocytosis is associated with a loss of cell viability, LDH and MTT assays were performed. No statistically significant difference in absolute LDH release 
was identified ( $n=7, p=0.24$; Figure 2D). Similarly, there was no difference in absolute MTT absorbance between control and activated optic nerve head astrocytes ( $n=7, p=0.43$; Figure 2E). These data suggest that reactive astrocytosis at the time point investigated does not cause any detectable reduction in cell viability.

\subsection{Different Classes of Antioxidants Elicit Specific Changes in NOX4, SOD2, and Nrf2 Protein Expression}

To determine the ability of optic nerve head astrocytes to respond to stimuli by changes in the expression of proteins involved in the endogenous antioxidant response, non-induced optic nerve head astrocyte cultures were exposed to different classes of antioxidants, and the protein expression levels of NOX4, SOD2 and Nrf2 were quantified by immunoblotting.

Specifically, astrocytes were treated with $0.005 \% \mathrm{Mn}-\mathrm{TM}-2-\mathrm{PyP}$ or PBS vehicle, $50 \mu \mathrm{M}$ resveratrol or $0.1 \%$ DMSO vehicle, $100 \mu \mathrm{M}$ Trolox or $0.1 \%$ ethanol vehicle, or $5 \mu \mathrm{M}$ xanthohumol or $0.01 \%$ DMSO vehicle for $24 \mathrm{~h}$. Concentrations were determined based on previous studies $[5,6,19]$, the published literature $[23,29,30]$ and cytotoxicity studies in optic nerve head astrocytes (Figure S1). Quantitative immunoblotting was performed to determine NOX4, SOD2, and Nrf2 protein expression.

Exposure to Mn-TM-2-PyP had no significant effect on NOX4 expression ( $n=3-6 ; p=0.47 ;$ Figure 3A), but resulted in a statistically significant 8.0-fold increase in SOD2 expression $(n=3-6 ; p<0.001$; Figure 3B) and a statistically significant 2.0-fold increase in Nrf2 expression ( $n=3-6 ; p<0.05$; Figure 3C).

A

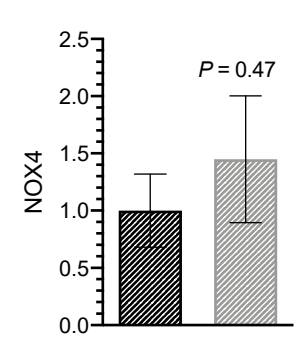

B

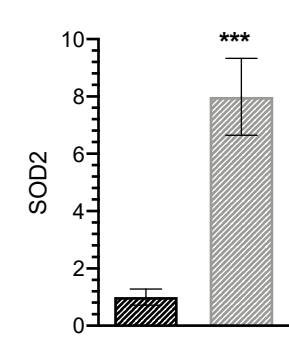

C

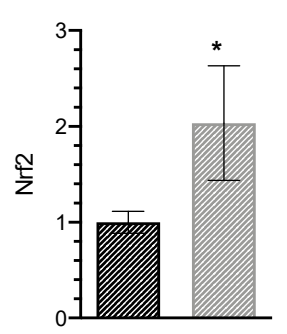

D

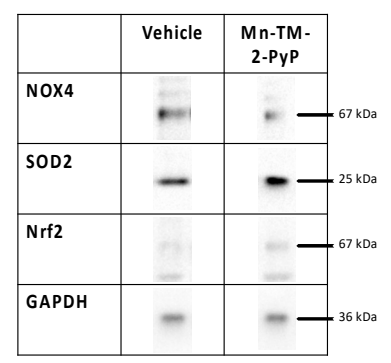

G

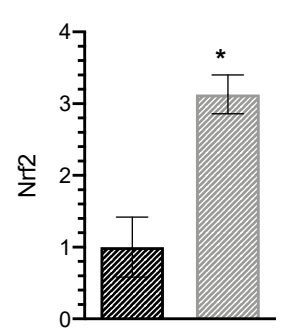

$\mathrm{H}$

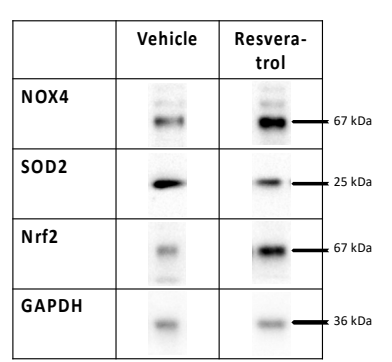

E

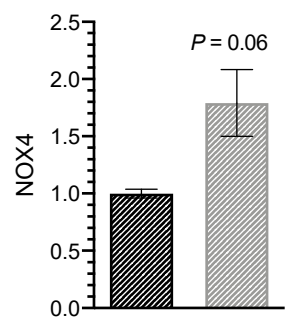

$\mathrm{F}$

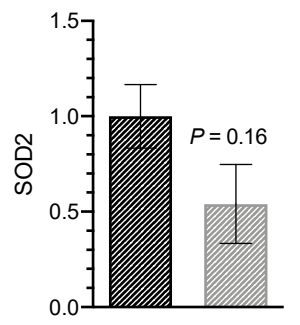

Vehicle ( $0.1 \%$ DMSO)

$50 \mu \mathrm{M}$ Resveratrol

Figure 3. Differential effects of Mn-TM-2-PyP and resveratrol on expression levels of Nrf2, SOD2, and NOX4 in control optic nerve head astrocytes. (A-C) Mn-TM-2-PyP elicited no significant effect on NOX4 expression ( $n=3-6 ; p=0.47)$; Figure 3A), but resulted in a statistically significant 8.0 -fold increase in SOD2 $(n=3-6 ; p<0.001)$ and a 2.0-fold increase in Nrf2 $(n=3-6 ; p<0.05)$. (D) Representative examples from quantitative immunoblotting are shown. (E-G) Treatment with resveratrol increased NOX4 protein expression 1.8-fold, but this effect did not reach statistical significance $(n=3, p=0.06)$. No significant effect on SOD2 expression was identified ( $n=3, p=0.16$; Figure 3E). In contrast, Nrf2 expression was elevated 3.1-fold $(n=3, p<0.05)$. Data are presented as mean \pm SEM. (h) Representative examples from quantitative immunoblotting are shown. ${ }^{*} p<0.05,{ }^{* * *} p<0.001$. 
Treatment with resveratrol increased NOX4 protein expression 1.8-fold, but this effect did not reach statistical significance ( $n=3, p=0.06$; Figure 3D). While resveratrol had no effect on SOD2 expression ( $n=3, p=0.16$; Figure 3E), Nrf2 expression was elevated 3.1-fold ( $n=3, p<0.05$; Figure 3E).

Trolox and xanthohumol did not exert any significant changes on expression of Nrf2, SOD2 or NOX4 (Table 1).

Table 1. Lack of effect of xanthohumol and Trolox on Nrf2, SOD2, and NOX4 expression in primary optic nerve head astrocytes.

\begin{tabular}{ccccc}
\hline Antioxidant & Condition & Nrf2 & SOD2 & NOX4 \\
\hline \multirow{2}{*}{ Trolox } & Vehicle $(0.1 \%$ ethanol $)$ & $1.00 \pm 0.22$ & $1.00 \pm 0.35$ & $1.00 \pm 0.04$ \\
& Trolox $(100 \mu \mathrm{M})$ & $1.62 \pm 0.02$ & $1.26 \pm 0.51$ & $1.79 \pm 0.29$ \\
& & $n=3, p=0.12$ & $n=3, p=0.70$ & $n=3, p=0.06$ \\
\hline \multirow{3}{*}{ Xanthohumol } & Vehicle $(0.01 \%$ DMSO) & $1.00 \pm 0.42$ & $1.00 \pm 0.17$ & $1.00 \pm 0.22$ \\
& Xanthohumol $(2.5 \mu \mathrm{M})$ & $0.98 \pm 0.29$ & $1.07 \pm 0.61$ & $0.73 \pm 0.32$ \\
& & $n=3, p=0.97$ & $n=3, p=0.91$ & $n=3, p=0.52$ \\
\hline
\end{tabular}

In a preliminary experiment, we also quantified catalase expression given the significant increase in SOD2 expression after exposure to Mn-TM-2-PyP. Treatment with Mn-TM-2-PyP resulted in a trend toward increased catalase expression ( $1.00 \pm 0.18$ vs. $2.53 \pm 0.82, n=3, p=0.14)$. Resveratrol (1.00 \pm 0.43 vs. $0.97 \pm 0.72, n=3, p=0.97)$, Trolox ( $1.00 \pm 0.44$ vs. $1.11 \pm 0.45, n=3, p=0.87)$ and xanthohumol $(1.00 \pm 0.43$ vs. $1.15 \pm 0.26, n=3, p=0.78$ ) had no effect on catalase expression (Figure S2A-H).

\subsection{Different Classes of Antioxidants Exert Varying Degrees of Glioprotection Against Reactive Astrocytosis- and $t B H P$ - Induced Oxidative Stress}

To assess the glioprotective effects of these antioxidants, cell viability of activated and control optic nerve astrocytes in response to increasing doses of exogenously-applied oxidative stress was quantified. MTT and LDH assays were employed as surrogate markers for cell viability.

Increased levels of cellular oxidative stress in activated optic nerve head astrocytes were reflected by a sensitization to exogenously applied oxidative stress insult, resulting in a left-ward shift of the dose-response curve to $t$ BHP (Figure 4).

$\mathrm{Mn}-\mathrm{TM}-2-\mathrm{PyP}$ resulted in potent glioprotection that completely prevented loss of cell viability in both control and activated astrocytes and no loss of cell viability could be detected in Mn-TM-2-PyP treated astrocytes by MTT ( $n=3$, Figure 4 A) and LDH release $(n=3$, Figure $4 \mathrm{~B})$ assays at $t$ BHP concentrations up to $500 \mu \mathrm{M}$.

Similarly, resveratrol exerted strong glioprotective effects that resulted in a statistically significant shift in the $\mathrm{IC}_{50}$ value for $t \mathrm{BHP}$ from $141 \pm 2.5 \mu \mathrm{M}$ to $175 \pm 2.4 \mu \mathrm{M}$ in control astrocytes $(n=4, p<0.001$; Figure $4 \mathrm{C})$ and $94.3 \pm 2.4 \mu \mathrm{M}$ to $141 \pm 1.5 \mu \mathrm{M}$ in activated astrocytes $(n=4, p<0.001$; Figure $4 \mathrm{C})$. These findings were confirmed in the LDH assay, which revealed shifts in the $\mathrm{EC}_{50}$ values from $196 \pm$ $4.1 \mu \mathrm{M}$ to $241 \pm 0.9 \mu \mathrm{M}$ in control astrocytes $(n=4-5, p<0.001$; Figure $4 \mathrm{D})$ and from $105 \pm 3.2 \mu \mathrm{M}$ to $208 \pm 6.5 \mu \mathrm{M}$ in activated astrocytes $(n=4-5, p<0.001$; Figure $4 \mathrm{D})$.

Glioprotection by xanthohumol was modest, shifting the $\mathrm{IC}_{50}$ for $t \mathrm{BHP}$ in the MTT assay by $15.9 \mu \mathrm{M}$ in control astrocytes and $14.5 \mu \mathrm{M}$ in activated astrocytes (Figure S3A, Table 2). Similarly, the LDH assay revealed shifts of $25.5 \mu \mathrm{M}$ and $32.9 \mu \mathrm{M}$ (Figure S3B, Table 2), respectively.

Treatment with $100 \mu \mathrm{M}$ Trolox caused a right-shift of both the MTT and LDH dose-response curves to $t \mathrm{BHP}$ that was proportional between control and activated optic nerve head astrocytes (Figure S3C,D, Table 2). 
A

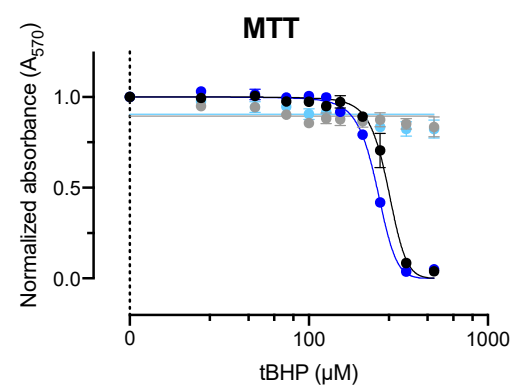

C

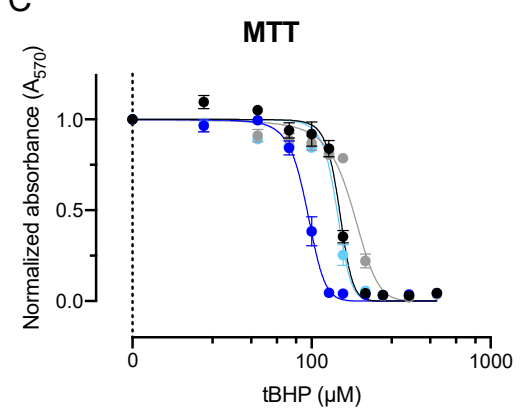

B

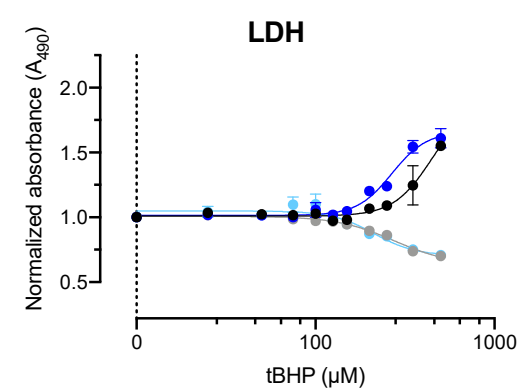

LDH

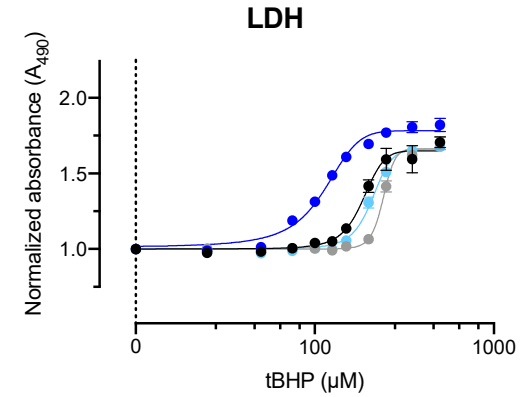

- $\quad$ CTRL + Vehicle (PBS)

CTRL + 0.05\% Mn-TM-2-PyP

$\rightarrow$ R.A. + Vehicle (PBS)

R.A. $+0.05 \%$ Mn-TM-2-PyP

- $\quad$ CTRL + Vehicle (0.1\% DMSO)

$\mathrm{CTRL}+50 \mu \mathrm{M}$ resveratrol

R.A. + Vehicle (0.1\% DMSO)

R.A. $+50 \mu \mathrm{M}$ resveratrol

Figure 4. Glioprotective effects of Mn-TM-2-PyP and resveratrol against reactive astrocytosis- and tBHP-induced oxidative stress. (A) Pretreatment of optic nerve head astrocytes with Mn-TM-2-PyP resulted in complete protection against both reactive astrocytosis- and $t \mathrm{BHP}$-induced oxidative stress, as determined by MTT assay. (B) Similarly, lactate dehydrogenase (LDH) assay revealed potent glioprotection by Mn-TM-2-PyP. (C) Resveratrol exerted strong glioprotective effects that resulted in a statistically significant shift in the $\mathrm{IC}_{50}$ value for $t \mathrm{BHP}$. (D) Similar shifts were observed in the $t \mathrm{BHP}$ dose-response curve in the LDH assay. Data are shown as mean \pm s.e.m. from three (Mn-TM-2-PyP) or four (resveratrol) separate experiments, with eight technical replicates per experiment.

Table 2. Trolox and xanthohumol are glioprotective against reactive astrocytosis- and chemically induced oxidative stress. (n.d. = not determined).

\begin{tabular}{cccccc}
\hline \multirow{2}{*}{ Antioxidant } & \multirow{2}{*}{ Condition } & \multicolumn{2}{c}{ Control } & \multicolumn{2}{c}{ Reactive Astrocytosis } \\
\cline { 3 - 6 } & & $\begin{array}{c}\text { MTT } \\
\mathbf{I C}_{\mathbf{5 0}} \text { (tBHP) }\end{array}$ & $\begin{array}{c}\text { LDH } \\
\mathbf{E C}_{\mathbf{5 0}} \text { (tBHP) }\end{array}$ & $\begin{array}{c}\text { MTT } \\
\text { IC }_{\mathbf{5 0}} \text { (tBHP) }\end{array}$ & $\begin{array}{c}\text { LDH } \\
\text { EC }_{\mathbf{5 0}} \text { (tBHP) }\end{array}$ \\
\cline { 3 - 6 } Trolox & Vehicle $(0.1 \%$ ethanol) & 73.0 & 126.7 & 50.0 & 93.1 \\
& Trolox $(100 \mu \mathrm{M})$ & 135.2 & n.d. & 99.3 & 210.3 \\
\hline \multirow{2}{*}{ Xanthohumol } & Vehicle $(0.01 \% \mathrm{DMSO})$ & 143.2 & 185.4 & 94.4 & 113.0 \\
& Xanthohumol $(2.5 \mu \mathrm{M})$ & 159.1 & 210.9 & 108.9 & 145.9 \\
\hline
\end{tabular}

\section{Discussion}

Astrocytes not only sustain neuronal function by providing trophic and metabolic support, but are important for cellular communication. One way for astrocytes to respond to a variety of stimuli is to undergo a process of activation, often referred to as reactive astrocytosis (for review, see [31]). Reactive astrocytes exhibit a phenotype of increased motility and proliferation associated with strong GFAP expression [32].

In the present study, we used GFAP expression as surrogate marker to confirm the induction of reactive astrocytosis in primary rat optic nerve head astrocytes (Figure 1). Increased GFAP expression following the induction of reactive astrocytosis by hyperbaric pressure was confirmed by immunocytochemistry (Figure 1A,F) and immunoblotting (Figure 1B). Several GFAP variants exist that exhibit distinct subcellular mRNA expression [33] and regulation of the intermediate filaments [34]. One study investigated GFAP isoforms in a mouse model for Alzheimer's Disease but did not 
identify any association with aging or reactive astrocytosis [35]. If or to what extent differential isoform expression underlies pathological changes or contributes to reactive astrocytosis in optic nerve head astrocytes remains unknown. Therefore, only overall GFAP expression was quantified herein. Future studies will address whether reactive astrocytosis in optic nerve head astrocytes is associated with differential changes in GFAP isoforms.

In the glaucomatous optic nerve head, reactive astrocytes undergo a characteristic remodeling of the actin cytoskeleton, contributing to optic nerve head cupping [36]. Cupping is an important clinical criterion for diagnosing and assessing the progression of glaucoma [37]. Here, reactive astrocytosis resulted in the shortening of F-actin fibers (Figure 1C) and increased G-actin fluorescence (Figure 1D), suggestive of a possible depolymerization of actin. These findings manifested as a noticeable disorganization of actin stress fibers. In control astrocytes, F-actin showed very orderly and linear parallel bundles, while it appeared very disorderly and in a more perpendicular orientation to neighboring bundles in activated optic nerve head astrocytes (Figure 1G). The F-to-G actin ratio (F-actin fiber length over $\mathrm{G}$-actin fluorescence) significantly decreased during reactive astrocytosis (Figure 1E). Altogether, these data are consistent with in vitro studies using 3D culture models [38], in vivo models using an acute controlled elevation of intraocular pressure (CEI) [39], and with the generally accepted notion that mechanical forces exerted on the human optic nerve head cause disruption of the actin cytoskeleton (reviewed in [40]).

The induction of reactive astrocytosis in cultured optic nerve head astrocytes resulted in the generation oxidative stress as quantified using two different approaches. CellROX ${ }^{\mathrm{TM}}$ Green becomes highly fluorescent upon oxidation by ROS and subsequent binding to DNA, resulting in strong nuclear and mitochondrial fluorescence (Figure 2A). Nuclear fluorescence was quantified by thresholding images and determining the fractional fluorescent nuclear area (Figure 2B). These findings were confirmed by the quantification of dichlorofluorescein fluorescence using plate-reader-based detection. Reactive astrocytosis resulted in a significant increase in dichlorofluorescein fluorescence. Combining a sublethal concentration of chemically induced oxidative stress by $100 \mu \mathrm{M} t \mathrm{BHP}$ with the induction of reactive astrocytosis resulted in a further proportional increase in fluorescence, while the prototypic ROS scavenger, Trolox, was able to prevent any increases (Figure 2C). Non-specific probes for ROS detection, such as dichlorofluorescein, can be oxidized by both peroxides and other ROS species. As the present study did not quantify the amount of cellular peroxide directly, it is impossible to estimate the contribution of peroxides to dichlorofluorescein fluorescence. However, the cell permeable dye, CellROX ${ }^{\circledR}$ Green, primarily detects radical oxygen and radical hydroxyl species [41]. These data suggest that reactive astrocytosis in vitro is associated with a gradual generation of ROS. Notably, reactive astrocytosis was not associated with a loss of cell viability, as determined by LDH and MTT assays.

One limitation of this study is that only one timepoint ( $16 \mathrm{~h}$ induction of reactive astrocytosis) was investigated. However, this timepoint was considered optimal for the subsequent assessment of antioxidant effects for two reasons: 1. astrocyte cultures could be maintained in complete, serum-containing media, while at the same time controlling for confounding effects of proliferation during the induction period; and 2. the induction of reactive astrocytosis was not associated with detectable loss of cell viability. The reactive astrocytosis-associated generation of elevated levels of oxidative stress is in accordance with a rigorous body of work that includes clinical studies and network analysis of human glaucomatous optic nerve head astrocytes [42], as well as in vivo studies [43,44].

Treatment with different classes of antioxidants resulted in differential effects on Nrf2, SOD2, and NOX4 proteins that were concurrent with their glioprotective properties against reactive astrocytosis- and oxidative stress-induced oxidative stress. These proteins were selected based on previously reported mechanisms of action of antioxidants involving Nrf2 and SOD2 [11,15,20,45]. NOX4 is one of the major isoforms of NADPH oxidases (reviewed in [46]). Expressed highly in brain astrocytes [47], NOX4 has been associated with subarachnoid hemorrhage-induced oxidative stress [48]. Furthermore, NOX4 is upregulated in response to transforming growth factor $\beta 1$ signaling in numerous 
cell types [49-52]. Given the effects of Mn-TM-2-PyP on SOD2 expression, we also quantified catalase expression after treatment with antioxidants in control optic nerve head astrocytes. Although not statistically significant, we observed a trend of increased catalase expression after treatment with Mn-TM-2-PyP, likely as a result of increased hydrogen peroxide levels generated from SOD2 activity.

Mn-TM-2-PyP exhibited the most potent glioprotective effects against reactive astrocytosis-induced oxidative stress, associated with a potent upregulation of Nrf2 and SOD2 expression. Mn-TM-2-PyP has previously been shown to be mitochondrially targeted, which may also contribute to its strong glioprotective effect [12]. Further studies must investigate whether this compound is entering the mitochondria of reactive optic nerve head astrocytes to evaluate its potential therapeutic effects. Manganese porphyrins have an established preclinical safety profile [24] and are currently used as an adjunctive therapy concurrent with radiation therapy (clinical trials \#NCT03386500 and \# NCT02655601). Their solubility and stability in aqueous buffers and formulations make manganese porphyrins, including Mn-TM-2-PyP, excellent candidates for a rapid translation to the clinic.

Resveratrol has been proposed to exert its antioxidant effects through a plethora of distinct mechanisms that include modulation of the endogenous antioxidant response element via Nrf2 [22,53], direct effects on $\mathrm{Cav}_{V}$ and other types of calcium channels [29], as well as direct antioxidant and antiperoxidant effects [54]. Notably, resveratrol has also been shown to inhibit histone deacetylases, which may alter the gene transcription of endogenous antioxidant enzymes [55]. Recently, an elegant study in rat optic nerve head astrocytes found that optic nerve head astrocytes respond to oxidative stress insult by proteolytic cleavage of Tau by caspases and the subsequent formation of neurofibrillary tangles, analogous to neurons [30]. Furthermore, the study showed that treatment with $100 \mu \mathrm{M}$ resveratrol was able to prevent Tau cleavage [30]. These data complement the findings reported herein that resveratrol is highly glioprotective, likely due to multiple intracellular mechanisms of action.

Xanthohumol exerts antioxidative effects by increasing Nrf2 translocation to the nucleus by facilitating the dissociation of Keap1 from Nrf2 [56]. Surprisingly, no effect on Nrf2 or any of the phase II antioxidant enzymes tested was identified in this study (Table 1). Xanthohumol belongs to the groups of flavonoids and, therefore, possesses direct ROS scavenging activity, which may be responsible for the observed modest glioprotective effects in optic nerve head astrocytes [45]. Additionally, it may be beneficial to investigate nuclear versus cytoplasmic Nrf2 expression with Xanthohumol to determine if it is increasing Nrf2 translocation in this cell type.

Overall, the expression of SOD2 and Nrf2 largely corresponded to the antioxidant effects of the compounds. Xanthohumol's inability to modulate the endogenous antioxidant proteins at a single time point tested corresponded to its minimal glioprotective effect observed in this study. Typically, the endogenous antioxidant system responds within a few hours to environmental changes. While resveratrol and Mn-TM-2-PyP both led to similar increases in Nrf2 expression, the ability of Mn-TM-2-PyP to sustain the significant upregulation of SOD2 at $24 \mathrm{~h}$ after Mn-TM-2-PyP treatment may explain its potent glioprotective and cytoprotective effects (present study; [19]).

Previous studies in human optic nerve head astrocytes have investigated Nrf2 expression primarily at the gene expression level in response to 4-hydroxynonenal treatment [57] or reported the response of heat shock protein $(\mathrm{Hsp}) \alpha_{\mathrm{B}}$-crystallin and Hsp27, fibronectin and connective tissue growth factor [58]. The present study is, to our knowledge, the first to describe the differential effects of different classes of antioxidants on NOX4, SOD2 and Nrf2 expression levels in optic nerve head astrocytes and to test their effects in a disease-relevant state of activation. In addition, the present study is the first to describe the expression of NOX4 in optic nerve head astrocytes. Future studies will address the expression of other isoforms of pro-oxidant NOX enzymes in optic nerve head astrocytes and their potential role in reactive astrocytosis.

\section{Conclusions}

Our results provide preliminary feasibility data supporting the preclinical development of antioxidants as novel therapeutics targeting the glaucomatous optic nerve head. By targeting the 
site of some of the pathological changes, glioprotective agents may be developed into efficacious therapies that can ultimately slow or prevent some of the deleterious pathologies associated with optic neuropathies.

Supplementary Materials: The following are available online at http://www.mdpi.com/2076-3921/9/4/324/s1, Figure S1: Cytotoxicity of antioxidants on optic nerve head astrocytes, Figure S2: Effects of antioxidants on expression levels of CAT in control optic nerve head astrocytes, Figure S3: Glioprotective effects of Trolox and xanthohumol against oxidative stress.

Author Contributions: Conceptualization, A.K.G., E.B.S., P.K. and S.K.; methodology, A.K.G., V.R.R., E.B.S., S.K.; software, V.J.W.; validation, A.K.G. and S.K.; formal analysis, A.K.G., V.R.R., S.K.; investigation, A.K.G., V.R.R., V.J.W., A.D.Z., J.F., P.K., E.B.S., S.K.; resources, E.B.S., P.K., S.K.; data curation, A.K.G., P.K., S.K.; writing-original draft preparation, A.K.G., S.K.; writing—review and editing, A.K.G., V.R.R., V.J.W., A.D.Z., J.F., P.K., E.B.S., S.K.; visualization, A.K.G., S.K.; supervision, S.K.; project administration, A.K.G., S.K.; funding acquisition, A.K.G., E.B.S., P.K., S.K. All authors have read and agreed to the published version of the manuscript.

Funding: This research was funded in part by The Glaucoma Foundation (SK), the Illinois Society for the Prevention of Blindness (AKG, SMR), the Dr. John P. and Therese E. Mulcahy Endowed Professorship in Ophthalmology (SK), the Richard A. Perritt M.D. Charitable Foundation and the Department of Veterans Affairs (grant I21RX001593; EBS). VRR received a travel grant from the Chicago Association for Research and Education in Science (CARES). Additional support by the Felix and Carmen Sabates Missouri Endowed Chair in Vision Research, a Challenge Grant from Research to Prevent Blindness and the National Institutes of Health (EY015672; PK) is gratefully acknowledged. The content is solely the responsibility of the authors and does not necessarily represent the official views of the National Institutes of Health. This material is the result of work supported with resources and the use of facilities at the Edward Hines Jr. VA Hospital, Hines, IL. The contents do not represent the views of the U.S. Department of Veterans Affairs or the United States Government. Additional support by Experimentica Ltd. and K\&P Scientific LLC is gratefully acknowledged. This work was previously published in part in a Neuroscience Master's Thesis entitled "Molecular and Biochemical Phenotypes Underlying Reactive Astrocytosis in Primary Optic Nerve Head Astrocytes" by Anita K. Ghosh of Loyola University Chicago.

Acknowledgments: The authors would like to thank the numerous volunteers in the Visual Neurobiology and Signal Transduction Laboratory for their contributions to our ongoing research program. Special thanks to Alexander Rockwell, Elliott Savarese, Cassandra Bacher and Bronte Root for excellent technical assistance.

Conflicts of Interest: Stock/equity ownership: SK (Experimentica Ltd., K\&P Scientific LLC); AKG (eyeNOS Inc.); Consulting: AKG (K\&P Scientific LLC, Experimentica Ltd.); SK (Experimentica Ltd.); Board membership: SK (Experimentica Inc.); AKG (eyeNOS Inc., Experimentica Inc.). SK conducts academic research in areas of interest similar to the business interests of Experimentica Ltd. and K\&P Scientific LLC. The terms of this arrangement have been reviewed and approved by Loyola University Chicago in accordance with its conflict of interest policy. The funders had no role in the design of the study; in the collection, analyses, or interpretation of data; in the writing of the manuscript, or in the decision to publish the results.

\section{References}

1. Bazargani, N.; Attwell, D. Astrocyte calcium signaling: The third wave. Nat. Neurosci. 2016, 19, $182-189$. [CrossRef]

2. Hernandez, M.R. The optic nerve head in glaucoma: Role of astrocytes in tissue remodeling. Prog. Retin. Eye Res. 2000, 19, 297-321. [CrossRef]

3. Wang, R.; Seifert, P.; Jakobs, T.C. Astrocytes in the Optic Nerve Head of Glaucomatous Mice Display a Characteristic Reactive Phenotype. Investig. Ophthalmol. Vis. Sci. 2017, 58, 924-932. [CrossRef] [PubMed]

4. Crawford Downs, J.; Roberts, M.D.; Sigal, I.A. Glaucomatous cupping of the lamina cribrosa: A review of the evidence for active progressive remodeling as a mechanism. Exp. Eye Res. 2011, 93, 133-140. [CrossRef] [PubMed]

5. Kaja, S.; Payne, A.J.; Naumchuk, Y.; Koulen, P. Quantification of Lactate Dehydrogenase for Cell Viability Testing Using Cell Lines and Primary Cultured Astrocytes. Curr. Protoc. Toxicol. 2017, 72, 2.26. 1-2.26. 10. [CrossRef]

6. Kaja, S.; Payne, A.J.; Naumchuk, Y.; Levy, D.; Zaidi, D.H.; Altman, A.M.; Nawazish, S.; Ghuman, J.K.; Gerdes, B.C.; Moore, M.A.; et al. Plate reader-based cell viability assays for glioprotection using primary rat optic nerve head astrocytes. Exp. Eye Res. 2015, 138, 159-166. [CrossRef]

7. Shim, M.S.; Kim, K.Y.; Bu, J.H.; Nam, H.S.; Jeong, S.W.; Park, T.L.; Ellisman, M.H.; Weinreb, R.N.; Ju, W.K. Elevated intracellular cAMP exacerbates vulnerability to oxidative stress in optic nerve head astrocytes. Cell Death Dis. 2018, 9, 285. [CrossRef] 
8. Noh, Y.H.; Kim, K.Y.; Shim, M.S.; Choi, S.H.; Choi, S.; Ellisman, M.H.; Weinreb, R.N.; Perkins, G.A.; Ju, W.K. Inhibition of oxidative stress by coenzyme Q10 increases mitochondrial mass and improves bioenergetic function in optic nerve head astrocytes. Cell Death Dis. 2013, 4, e820. [CrossRef]

9. Kernt, M.; Arend, N.; Buerger, A.; Mann, T.; Haritoglou, C.; Ulbig, M.W.; Kampik, A.; Hirneiss, C. Idebenone prevents human optic nerve head astrocytes from oxidative stress, apoptosis, and senescence by stabilizing BAX/Bcl-2 ratio. J. Glaucoma 2013, 22, 404-412. [CrossRef]

10. Kernt, M.; Neubauer, A.S.; Eibl, K.H.; Wolf, A.; Ulbig, M.W.; Kampik, A.; Hirneiss, C. Minocycline is cytoprotective in human trabecular meshwork cells and optic nerve head astrocytes by increasing expression of XIAP, survivin, and Bcl-2. Clin. Ophthalmol. 2010, 4, 591-604. [CrossRef]

11. Ma, Q. Role of nrf2 in oxidative stress and toxicity. Annu. Rev. Pharm. Toxicol. 2013, 53, 401-426. [CrossRef] [PubMed]

12. Lahaye, D.; Muthukumaran, K.; Hung, C.H.; Gryko, D.; Reboucas, J.S.; Spasojevic, I.; Batinic-Haberle, I.; Lindsey, J.S. Design and synthesis of manganese porphyrins with tailored lipophilicity: Investigation of redox properties and superoxide dismutase activity. Bioorg. Med. Chem. 2007, 15, 7066-7086. [CrossRef] [PubMed]

13. Mackensen, G.B.; Patel, M.; Sheng, H.; Calvi, C.L.; Batinic-Haberle, I.; Day, B.J.; Liang, L.P.; Fridovich, I.; Crapo, J.D.; Pearlstein, R.D.; et al. Neuroprotection from delayed postischemic administration of a metalloporphyrin catalytic antioxidant. J. Neurosci. 2001, 21, 4582-4592. [CrossRef] [PubMed]

14. Piganelli, J.D.; Flores, S.C.; Cruz, C.; Koepp, J.; Batinic-Haberle, I.; Crapo, J.; Day, B.; Kachadourian, R.; Young, R.; Bradley, B.; et al. A metalloporphyrin-based superoxide dismutase mimic inhibits adoptive transfer of autoimmune diabetes by a diabetogenic T-cell clone. Diabetes 2002, 51, 347-355. [CrossRef]

15. Vujaskovic, Z.; Batinic-Haberle, I.; Rabbani, Z.N.; Feng, Q.F.; Kang, S.K.; Spasojevic, I.; Samulski, T.V.; Fridovich, I.; Dewhirst, M.W.; Anscher, M.S. A small molecular weight catalytic metalloporphyrin antioxidant with superoxide dismutase (SOD) mimetic properties protects lungs from radiation-induced injury. Free Radic. Biol. Med. 2002, 33, 857-863. [CrossRef]

16. Bloodsworth, A.; O’Donnell, V.B.; Batinic-Haberle, I.; Chumley, P.H.; Hurt, J.B.; Day, B.J.; Crow, J.P.; Freeman, B.A. Manganese-porphyrin reactions with lipids and lipoproteins. Free Radic. Biol. Med. 2000, 28, 1017-1029. [CrossRef]

17. Ferrer-Sueta, G.; Batinic-Haberle, I.; Spasojevic, I.; Fridovich, I.; Radi, R. Catalytic scavenging of peroxynitrite by isomeric Mn(III) N-methylpyridylporphyrins in the presence of reductants. Chem. Res. Toxicol. 1999, 12, 442-449. [CrossRef] [PubMed]

18. Day, B.J.; Batinic-Haberle, I.; Crapo, J.D. Metalloporphyrins are potent inhibitors of lipid peroxidation. Free Radic. Biol. Med. 1999, 26, 730-736. [CrossRef]

19. Ziniauskaite, A.; Ragauskas, S.; Ghosh, A.K.; Thapa, R.; Roessler, A.E.; Koulen, P.; Kalesnykas, G.; Hakkarainen, J.J.; Kaja, S. Manganese(III) tetrakis(1-methyl-4-pyridyl) porphyrin, a superoxide dismutase mimetic, reduces disease severity in in vitro and in vivo models for dry-eye disease. Ocul. Surf. 2019, 17, 257-264. [CrossRef]

20. Bhat, K.P.L.; Kosmeder, J.W., 2nd; Pezzuto, J.M. Biological effects of resveratrol. Antioxid. Redox Signal. 2001, 3, 1041-1064. [CrossRef]

21. Kong, A.N.; Yu, R.; Hebbar, V.; Chen, C.; Owuor, E.; Hu, R.; Ee, R.; Mandlekar, S. Signal transduction events elicited by cancer prevention compounds. Mutat. Res. 2001, 480-481, 231-241. [CrossRef]

22. Chen, C.Y.; Jang, J.H.; Li, M.H.; Surh, Y.J. Resveratrol upregulates heme oxygenase-1 expression via activation of NF-E2-related factor 2 in PC12 cells. Biochem. Biophys. Res. Commun. 2005, 331, 993-1000. [CrossRef]

23. Liu, M.; Hansen, P.E.; Wang, G.; Qiu, L.; Dong, J.; Yin, H.; Qian, Z.; Yang, M.; Miao, J. Pharmacological profile of xanthohumol, a prenylated flavonoid from hops (Humulus lupulus). Molecules 2015, 20, 754-779. [CrossRef]

24. Badarinath, A.V.; Rao, K.M.; Chetty CM, S.; Ramkanth ST VS, R.; Rajan TV, S.; Gnanaprakash, K. A Review on In-vitro Antioxidant Methods: Comparisions, Correlations and Considerations. Int. J. Pharmtech. Res. 2010, 2, 1276-1285.

25. Ismail Hamad, N.A.; Pekmez, M.; Karaer, S.; Temizkan, G. Intracellular scavenging activity of Trolox (6-hydroxy-2,5,7,8-tetramethylchromane-2-carboxylic acid) in the fission yeast, Schizosaccharomyces pombe. J. Nat. Sci. Biol. Med. 2010, 1, 16-21. [CrossRef] [PubMed] 
26. Kaja, S.; Payne, A.J.; Patel, K.R.; Naumchuk, Y.; Koulen, P. Differential subcellular Ca2+ signaling in a highly specialized subpopulation of astrocytes. Exp. Neurol. 2015, 265, 59-68. [CrossRef] [PubMed]

27. Lowry, O.H.; Rosebrough, N.J.; Farr, A.L.; Randall, R.J. Protein measurement with the Folin phenol reagent. J. Biol. Chem. 1951, 193, 265-275.

28. Kaja, S.; Duncan, R.S.; Longoria, S.; Hilgenberg, J.D.; Payne, A.J.; Desai, N.M.; Parikh, R.A.; Burroughs, S.L.; Gregg, E.V.; Goad, D.L.; et al. Novel mechanism of increased Ca2+ release following oxidative stress in neuronal cells involves type 2 inositol-1,4,5-trisphosphate receptors. Neuroscience 2011, 175, 281-291. [CrossRef]

29. McCalley, A.E.; Kaja, S.; Payne, A.J.; Koulen, P. Resveratrol and calcium signaling: Molecular mechanisms and clinical relevance. Molecules 2014, 19,7327-7340. [CrossRef]

30. Means, J.C.; Lopez, A.A.; Koulen, P. Resveratrol Protects Optic Nerve Head Astrocytes from Oxidative Stress-Induced Cell Death by Preventing Caspase-3 Activation, Tau Dephosphorylation at Ser(422) and Formation of Misfolded Protein Aggregates. Cell. Mol. Neurobiol. 2020. [CrossRef]

31. Pekny, M.; Pekna, M. Astrocyte reactivity and reactive astrogliosis: Costs and benefits. Physiol. Rev. 2014, 94, 1077-1098. [CrossRef] [PubMed]

32. Hol, E.M.; Pekny, M. Glial fibrillary acidic protein (GFAP) and the astrocyte intermediate filament system in diseases of the central nervous system. Curr. Opin. Cell Biol. 2015, 32, 121-130. [CrossRef] [PubMed]

33. Thomsen, R.; Daugaard, T.F.; Holm, I.E.; Nielsen, A.L. Alternative mRNA splicing from the glial fibrillary acidic protein (GFAP) gene generates isoforms with distinct subcellular mRNA localization patterns in astrocytes. PLoS ONE 2013, 8, e72110. [CrossRef]

34. Moeton, M.; Stassen, O.M.; Sluijs, J.A.; van der Meer, V.W.; Kluivers, L.J.; van Hoorn, H.; Schmidt, T.; Reits, E.A.; van Strien, M.E.; Hol, E.M. GFAP isoforms control intermediate filament network dynamics, cell morphology, and focal adhesions. Cell. Mol. Life Sci. 2016, 73, 4101-4120. [CrossRef]

35. Kamphuis, W.; Mamber, C.; Moeton, M.; Kooijman, L.; Sluijs, J.A.; Jansen, A.H.; Verveer, M.; de Groot, L.R.; Smith, V.D.; Rangarajan, S.; et al. GFAP isoforms in adult mouse brain with a focus on neurogenic astrocytes and reactive astrogliosis in mouse models of Alzheimer disease. PLoS ONE 2012, 7, e42823. [CrossRef] [PubMed]

36. Hernandez, M.R.; Ye, H. Glaucoma: Changes in extracellular matrix in the optic nerve head. Ann. Med. 1993, 25, 309-315. [CrossRef]

37. Iyer, J.; Vianna, J.R.; Chauhan, B.C.; Quigley, H.A. Toward a new definition of glaucomatous optic neuropathy for clinical research. Curr. Opin. Ophthalmol. 2020, 31, 85-90. [CrossRef]

38. Mulvihill, J.J.E.; Raykin, J.; Snider, E.J.; Schildmeyer, L.A.; Zaman, I.; Platt, M.O.; Kelly, D.J.; Ethier, C.R. Development of a Platform for Studying 3D Astrocyte Mechanobiology: Compression of Astrocytes in Collagen Gels. Ann. Biomed. Eng. 2018, 46, 365-374. [CrossRef]

39. Tehrani, S.; Davis, L.; Cepurna, W.O.; Delf, R.K.; Lozano, D.C.; Choe, T.E.; Johnson, E.C.; Morrison, J.C. Optic Nerve Head Astrocytes Display Axon-Dependent and -Independent Reactivity in Response to Acutely Elevated Intraocular Pressure. Investig. Ophthalmol. Vis. Sci. 2019, 60, 312-321. [CrossRef]

40. Downs, J.C. Optic nerve head biomechanics in aging and disease. Exp. Eye Res. 2015, 133, 19-29. [CrossRef]

41. Choi, H.; Yang, Z.; Weisshaar, J.C. Single-cell, real-time detection of oxidative stress induced in Escherichia coli by the antimicrobial peptide CM15. Proc. Natl. Acad. Sci. USA 2015, 112, E303-E310. [CrossRef] [PubMed]

42. Nikolskaya, T.; Nikolsky, Y.; Serebryiskaya, T.; Zvereva, S.; Sviridov, E.; Dezso, Z.; Rahkmatulin, E.; Brennan, R.J.; Yankovsky, N.; Bhattacharya, S.K.; et al. Network analysis of human glaucomatous optic nerve head astrocytes. BMC Med. Genom. 2009, 2, 24. [CrossRef] [PubMed]

43. Chidlow, G.; Wood, J.P.M.; Casson, R.J. Investigations into Hypoxia and Oxidative Stress at the Optic Nerve Head in a Rat Model of Glaucoma Front. Neurosci. 2017, 11, 478. [CrossRef]

44. Moreno, M.C.; Campanelli, J.; Sande, P.; Sanez, D.A.; Keller Sarmiento, M.I.; Rosenstein, R.E. Retinal oxidative stress induced by high intraocular pressure. Free Radic. Biol. Med. 2004, 37, 803-812. [CrossRef]

45. Yao, J.; Zhang, B.; Ge, C.; Peng, S.; Fang, J. Xanthohumol, a Polyphenol Chalcone Present in Hops, Activating Nrf2 Enzymes To Confer Protection against Oxidative Damage in PC12 Cells. J. Agric. Food Chem. 2015, 63, 1521-1531. [CrossRef] [PubMed]

46. Bedard, K.; Krause, K.H. The NOX family of ROS-generating NADPH oxidases: Physiology and pathophysiology. Physiol. Rev. 2007, 87, 245-313. [CrossRef] 
47. Jiang, T.; Cadenas, E. Astrocytic metabolic and inflammatory changes as a function of age. Aging Cell 2014, 13, 1059-1067. [CrossRef]

48. Zhang, L.; Li, Z.; Feng, D.; Shen, H.; Tian, X.; Li, H.; Wang, Z.; Chen, G. Involvement of Nox2 and Nox4 NADPH oxidases in early brain injury after subarachnoid hemorrhage. Free Radic. Res. 2017, 51, 316-328. [CrossRef]

49. Brown, K.D.; Shah, M.H.; Liu, G.S.; Chan, E.C.; Crowston, J.G.; Peshavariya, H.M. Transforming Growth Factor beta1-Induced NADPH Oxidase-4 Expression and Fibrotic Response in Conjunctival Fibroblasts. Investig. Ophthalmol. Vis. Sci. 2017, 58, 3011-3017. [CrossRef]

50. Sturrock, A.; Cahill, B.; Norman, K.; Huecksteadt, T.P.; Hill, K.; Sanders, K.; Karwande, S.V.; Stringham, J.C.; Bull, D.A.; Gleich, M.; et al. Transforming growth factor-beta1 induces Nox4 NAD(P)H oxidase and reactive oxygen species-dependent proliferation in human pulmonary artery smooth muscle cells. Am. J. Physiol. Lung Cell. Mol. Physiol. 2006, 290, L661-L673. [CrossRef]

51. Carmona-Cuenca, I.; Roncero, C.; Sancho, P.; Caja, L.; Fausto, N.; Fernandez, M.; Fabregat, I. Upregulation of the NADPH oxidase NOX4 by TGF-beta in hepatocytes is required for its pro-apoptotic activity. J. Hepatol. 2008, 49, 965-976. [CrossRef] [PubMed]

52. Lou, Z.; Wang, A.P.; Duan, X.M.; Hu, G.H.; Song, G.L.; Zuo, M.L.; Yang, Z.B. Upregulation of NOX2 and NOX4 Mediated by TGF-beta Signaling Pathway Exacerbates Cerebral Ischemia/Reperfusion Oxidative Stress Injury. Cell. Physiol. Biochem. 2018, 46, 2103-2113. [CrossRef]

53. Rosa, P.M.; Martins, L.A.M.; Souza, D.O.; Quincozes-Santos, A. Glioprotective Effect of Resveratrol: An Emerging Therapeutic Role for Oligodendroglial Cells. Mol. Neurobiol. 2018, 55, 2967-2978. [CrossRef]

54. Khanduja, K.L.; Bhardwaj, A. Stable free radical scavenging and antiperoxidative properties of resveratrol compared in vitro with some other bioflavonoids. Indian, J. Biochem. Biophys. 2003, 40, 416-422.

55. Venturelli, S.; Berger, A.; Böcker, A.; Busch, C.; Weiland, T.; Noor, S.; Bischoff, S.C. Resveratrol as a Pan-HDAC Inhibitor Alters the Acetylation Status of Jistone Proteins in Human-Derived Hepatoblastoma Cells. PLoS ONE 2013, 8. [CrossRef]

56. Dietz, B.M.; Kang, Y.H.; Liu, G.; Eggler, A.L.; Yao, P.; Chadwick, L.R.; Pauli, G.F.; Farnsworth, N.R.; Mesecar, A.D.; van Breemen, R.B.; et al. Xanthohumol isolated from Humulus lupulus Inhibits menadione-induced DNA damage through induction of quinone reductase. Chem. Res. Toxicol. 2005, 18, 1296-1305. [CrossRef]

57. Malone, P.E.; Hernandez, M.R. 4-Hydroxynonenal, a product of oxidative stress, leads to an antioxidant response in optic nerve head astrocytes. Exp. Eye Res. 2007, 84, 444-454. [CrossRef]

58. Yu, A.L.; Moriniere, J.; Welge-Lussen, U. TGF-beta(2)- and $\mathrm{H}(2) \mathrm{O}(2)$-induced biological changes in optic nerve head astrocytes are reduced by the antioxidant alpha-lipoic acid. Ophthalmic. Res. 2012, 48, 156-164. [CrossRef]

(C) 2020 by the authors. Licensee MDPI, Basel, Switzerland. This article is an open access article distributed under the terms and conditions of the Creative Commons Attribution (CC BY) license (http://creativecommons.org/licenses/by/4.0/). 